\title{
Impact of Bilingual Language and Their Proficiency on Role Behaviors in Strategic Decision-Making Meetings
}

\section{Bertha Du-Babcock}

\author{
Wenzao Ursuline University of Languages, Kaohsiung, Taiwan
}

Objectives: This paper investigates whether (1) Hong Kong bilinguals exhibit different role behaviors in interconnected Cantonese (L1) and English (L2) strategic decision-making meetings; (2) individuals with higher L2 proficiency exhibit more task-facilitating role behaviors, while individuals with lower L2 proficiency likely exhibit more relational-maintenance role behaviors; and (3) English proficiency affect the role behavior of Hong Kong bilinguals.

Methods: The study adopted a schema developed by Benne and Sheats and Barker, Wahlers, Watson, \& Kibler. The data consisted of 22 meeting transcripts with a total copra of 65,397 words of English dialogs and 120,998 Chinese characters. The number and frequency of the role behaviors of each participant were codified, counted, and compared to examine the impact of language use and $\mathrm{L} 2$ proficiency on role behaviors.

Results: The results showed that Hong Kong bilinguals performed more task-facilitating and relational- maintenance role behaviors in Cantonese meetings than in English meetings. Findings also revealed that L2 proficiency influenced task-facilitating role behaviors when making decisions in English and that the individuals who performed more task-facilitating role behaviors in English meetings had a tendency to perform more task-facilitating role behaviors in Cantonese meetings.

Conclusion: The study clarifies when and why Hong Kong bilinguals communicate differently in their L1 and L2 meetings. The study provides possible markers for improving the quantity and quality of intercultural communication. When bilinguals with intermediate L2 proficiency participate in an intercultural meeting requiring interactive decision making, the challenge is to create a communication structure where their communication potential can be more fully utilized.

Key Words: Functional Role Behavior, Task-Oriented Role Behavior, Maintenance Relationship Role Behavior, Strategic Decision-Making Meeting, English Proficiency

Received: Sept 4, 2019 Revised: Nov 5, 2019 Accepted: Nov 22, 2019 Corresponding author: Bertha Du-Babcock English Department, Wenzao Ursuline University of Languages, 900, MinTzu 1st Road, San-Min District, Kaohsiung, Taiwan Tel: +886-7-3426031, E-mail: enbertha@gmail.com

This is an Open Access article distributed under the terms of the Creative Commons Attribution Non-Commercial License (http://creativecommons.org/licenses/ by-nc/4.0/) which permits unrestricted non-commercial use, distribution, and reproduction in any medium, provided the original work is properly cited.

Copyright $\odot 2020$ Korean Association for Business Communication.

\section{Introduction}

Communicating in a bilingual or even a multilingual work environment is inevitable nowadays (Du-Babcock, 1999, 2006; Rogerson-Revell, 1999, 2008). As English is an international business lingua franca (Du-Babcock, 2013; Du-Babcock \& Tanaka, 2013; Nickerson, 2005), the opportunities for bilinguals in non-native English speaking countries using English as medium of communication to exchange information and 
make decisions in different business activities has been largely increased. It is believed that bilinguals' second language (L2) proficiency has significant and direct impact on their functional role behaviors in decision-making, especially when the decision-making process is conducted in a second language. Past research on decision-making behaviors and roles in business activities (e.g., Bales, 1950, 1958; Bavelas, 1950; Chen, Lin, \& Sawangpattanakul, 2011; Hirokawa, 1988; Perks, Cooper, \& Jones, 2005; Rose, Ramalu, Uli, \& Kumar, 2010) has mainly focused on individualistic countries, especially the United States where decision-making processes were usually conducted in participants' first language, English.

Roles can be defined as more or less stated functions/duties or responsibilities that guide individual behavior and regulate intra-group interaction (Hare \& Davies, 1994). Researchers such as Pugh and Redding (1985) and Westwood (1992) have concluded that organizations and individual roles within organizations are less well- defined in South-East Asia. To fill in this research gap, the present study examines the functional role behaviors of bilingual Chinese in a collectivistic society (Hong Kong) where bilingual Hong Kong Chinese participated in their first-and second-language decision-making meetings.

Being a British colony from 1841-1997, Hong Kong bilingual Chinese are used to communicating in both Cantonese (L1) and English (L2) concurrently at workplace. Given this uniqueness of the language environment in Hong Kong, the bilingual Chinese live in a collective culture and speak Cantonese in general and English with native-English speakers and non-Cantonese speakers in business contexts (Du-Babcock, 1999, 2006). Thus, living under such a language environment, Hong Kong people cannot help but monitor and unconsciously code switch between their first-and second-language messages when they use these two languages to exchange information and make decisions (Du-Babcock, 1999, 2006). With its prominence as an international financial hub and its pattern of bilingual and simultaneous language use, Hong Kong is an ideal research site for a comparison of functional role behaviors of the Hong Kong bilingual Chinese using their first language (Cantonese) and second language (English) in decision-making processes.

The present study is a first effort to look at small-group role behaviors in a collectivistic culture (Hong Kong) and to compare the patterns in L1 and L2 meetings. Consequently, the thrust of the study extends Du-Babcock's research stream on first-and second-language communication in group decision makings (see for example, Du-Babcock, 1999, 2006) and investigates if and how the L2 competencies of bilinguals affect the distribution of small-group functional role behaviors.

\section{Theoretical Framework}

The study draws from various theoretical frameworks including Benne and Sheats's (1948) functional approach theory, Bales's (1950) interaction process approach, and Hirokawa's (1988) small-group communication approach. Drawing on Benne and Sheats, Bales (1950) developed Interaction Process Analysis (IPA) - a framework to study small-group behavior by classifying individual role behavior into two dimensional roles that are task and maintenance role behavior. IPA remains a significant contribution to research in small-group behaviors. This technique allows observers or participants to interpret or classify the events in a group setting. He developed a useful 12 categories system for observing small-group behavior that is comprehensive and well validated by research (Appendix 1). Bales theorized about the equilibrium nature of small groups and typical interaction phases through which groups progress. In this connection, Bales believed that the success of the group performance depends on how well the group communicates, and thereby he theorized that research should examine a group's communication to see the functions group members play during discussion. Consequently, he proposed a coding scheme with 12 categories. The task-facilitating role behavior consists of 12 sub-roles that relate to the facilitating and coordination of the tasks individuals are involved in (Appendix 1 for categories and examples). These 12 sub-roles are Information Giver, Information Seeker, Orienteer, Initiator/Contributor, Opinion Giver, Opinion Seeker, Elaborator, Coordinator, Evaluator- Critic, Energizer, Procedural Technician, and Recorder.

As for the group building and maintenance role behavior, seven sub-roles are classified to maintain smooth function of the group (Appendix 2). These sub-roles are Harmonizer, Compromiser, Gatekeeper, Follower, Encourager, Confirmer, and Response Giver. When it comes to the self-centered role behavior, Diedrich and Dye (1972) classified self-centered role behaviors into 8 sub-roles: Aggressor; Blocker; Recognition Seeker; Dominator; Avoider; Playboy and Playgirl; Self-confessor; and Help Seeker/Special-interest Pleader. Due to the nature of the decision-making meetings, less than five of the self-centered role behaviors were played by group members. With such an insignificant role behavior, self-centered role behaviors will not be analyzed in this paper.

\section{Literature Review}

To investigate the impact of language use and English proficiency on functional role behaviors, the literature review is divided into three parts: (1) L1 and L2 communication; (2) the effect of 
language proficiency on communication; and (3) small-group dynamics and functional roles in the simulated decision-making meetings.

\section{L1 and L2 Communication}

Research examining the impact of language use on communication behaviors has focused on English intercultural communication in which Asians were speaking in their second language. Past research has found that native and nonnative English speakers exhibited different communication behaviors in intercultural meetings. Yamada (1990) studied the distribution of turn-taking behaviors and found that the Japanese business professionals were less active than were their Western counterparts. Bilbow $(1996,2002)$ and Rogerson-Revell $(1999,2008)$ investigated the meeting interaction between native English-speaking expatriates and local Cantonese-speaking Chinese in large multinational corporations. These two intercultural communication studies concluded that Chinese are not as verbally active as Westerners in English intercultural meetings.

Du-Babcock's $(1999,2006)$ study was the first empirical research that directly compared L1 and L2 communication of bilingual Hong Kong Chinese. In this empirical study, she drew on the notion that the language use can influence and change message content and communication behavior. The findings indicated that there was a moderate relationship between high $\mathrm{L} 2$ proficiency and the participation rate during the meetings. The findings of her 1999 study also provided explanations for the ways in which individuals interacted differently when they used their first language as compared to when they used their second language to make decisions in intracultural small-group decision-making meetings. Her intercultural decision-making study (Du-Babcock, 2003, 2005) compared the turn-taking behaviors of Asians and Westerners in intracultural and intercultural English meetings. The results concluded that Hong Kong bilingual Chinese exhibited different communication behaviors when participating in a homogeneous (intracultural) as compared with a heterogeneous (intercultural) group decision-making meeting. Taken together, these studies suggest that language use has a significant impact on the communication behaviors of Hong Kong bilingual Chinese.

\section{Second-Language Proficiency and Communication}

Second-language proficiency is a determining factor that is likely to affect the communication behaviors of bilingual business professionals. Prior studies have established that language proficiency is positively related to communication effectiveness (e.g., Du-Babcock, 1999, 2006, 2013; Du-Babcock \& Tanaka, 2013; Rogerson-Revell, 1999, 2008). That is, individuals with higher language proficiency are able to communicate more easily and more effectively over a wider range of topics than those of lower competency. Speakers with low L2 proficiency communicate fewer ideas and provide less detailed descriptions than do speakers with high L2 proficiency in that the low proficient individuals may engage in language simplification and avoidance strategies by adopting a variety of practices that either alter or reduce content and ignore difficult-to-express subjects.

In Du-Babcock's $(1999,2006)$ study, the language proficiency-based explanation argued that it was the first- and second-language proficiency differentials that triggered the various communication behaviors of the Cantonese bilinguals. The results also indicated that individuals with higher secondlanguage proficiency participated at a higher rate in second-language meetings than did individuals with lower second-language proficiency. Nonetheless, the findings further revealed that although low second-language-proficient individuals might have contributed fewer ideas, they were able to participate in and contribute ideas to their designated functional areas at the decision-making meetings. This meant that the low-second-language-proficient individuals could maintain sufficient involvement in the second-language meetings.

The overall thrust of the literature is that L2 proficiency at either very high levels (full bilingual competency) or at very low L2 competency directly impacts L2 communication. When a lower- competency L2 speaker is present in a communication environment, this individual may be excluded from the conversation, especially in a communication environment where interactive listening skills are required. Lacking interactive listening skills, the low proficient L2 communicator may find it difficult to actively participate in spontaneous conversations. In other words, the low L2 proficient individual can send prepared messages but does not possess the ability to respond to questions or unanticipated spontaneous comments. While organizing ideas to present, this individual cannot effectively listen to other speakers. A double bind situation is created - it is a dilemma of having to listen to and compose ideas simultaneously. As a result, low-level L2 proficiency individuals do not receive requisite amount of information to activate active participation, and therefore, becomes silent in multi-party communication.

Du-Babcock's research also suggests that native-like communication abilities are not critical for L2 speakers to efficiently communicate in L2. The ability to use L2 is conditioned by topic variety, familiarity, and predictability. In looking at communication exchange among expatriates and Taiwanese employees, Du-Babcock and Babcock (1996) found that creating a predictable communication environment facilitated more effective L2 communication so that Taiwanese engineers could communi- 
cate with both European and American managers in video-conferences and telephone conversations as long as the dialogs were confined to their areas of engineering expertise. For the present study, the literature review has established that L2 proficiency impacts L2 communication. In addition, L2 proficiency is a complex phenomenon having multiple dimensions and, to be fully understood, needs to be looked at from different perspectives.

\section{Small-Group Dynamics and Functional Roles in the} Decision-making Meetings

The prior writing and classic empirical studies on role behaviors (e.g., Bales, 1950, 1958; Bavelas, 1950; Hirokawa, 1988) have been centered in individualistic countries. These studies have established that task-facilitating and relational-maintenance roles must be present for a group to achieve its goals but that varying patterns of task-facilitating and relational-maintenance role distribution can produce high productivity groups. While task-oriented role behaviors focus on roles that facilitate problem solving and decision making, the relational-maintenance role behaviors emphasize roles that enhance relationships and resolve conflicts.

Barker et al. (1995) noted that the success of a business meeting depends on three crucial elements in group dynamics, namely role-playing, group norms, and group decision- making. The effectiveness of a decision-making process is a result of participants who closely observe the "rules" of the "game" (i.e., the implicit or explicit rules of a business meeting) and the proper roles in achieving the group goal. The roles people play in meetings can be classified in three categories: task-facilitating roles, relational-maintenance roles, and self-oriented roles (Barker et al., 1995; Benne \& Sheats, 1948).

Benne and Sheats (1948) developed a list of functional role behaviors that members played in groups, and they further divided them into three major categories: (1) group task roles, (2) group building and maintenance roles, and (3) self-centered roles. Group task roles are those behaviors related to the accomplishment of the group's task or achievement goal, which refers to the major outcome or product that the group intends to make. Moreover, group task role behaviors focus on roles that facilitate problem solving, communication, use of information, and decision making; whereas, group building and maintenance role behavior emphasizes the improvement or maintenance of interpersonal relationships, resolve of conflicts, and thereby, maintain smooth function of the groups. Both task and maintenance roles help groups to pursue their goals. The self-centered role behavior focuses on individual and personal goals and needs rather than the needs of the groups. Group members playing individual roles intend to satisfy their own personal needs and desire. Thus, self-oriented role behaviors are negative functional roles that can be counterproductive and hinder the groups to achieve their goals and may operate at the conscious or unconscious level. During the course of action, each individual enacts more than one role.

Based on the literature reviewed, three sets of research questions are put forward. They are:

RQ1: Do Hong Kong bilingual Chinese exhibit similar or different role behaviors in interconnected L1 and L2 strategic decision-making meetings?

RQ2: Do individuals with higher second-language proficiency exhibit more task-facilitating role behaviors, while individuals with lower second-language proficiency likely exhibit more relational-maintenance role behaviors?

RQ3: Does English proficiency affect the role behavior of Hong Kong Chinese bilinguals?

\section{Methods}

\section{Research Participants}

The data set for the study consists of transcripts of the dialogs of 11 groups (made up of five- to seven- persons per group) of Hong Kong Chinese bilinguals. These groups competed in a computerized business strategy simulation and the dialogs capture the strategic development process as it evolved in the group meetings. Sixty-six individuals $(\mathrm{N}=66)$ enrolled in two sessions of the Strategic Management course at a Hong Kong tertiary institute were chosen to participate in the study. Although random group assignment was not possible, the participants were exposed to comparable subject matter and possessed adequate second-language proficiency in that the second- language proficiency levels of the group members ranged between 4 and 6 on a self-reported 7-point Likert scale. Consequently, all group members possessed adequate vocabulary and interactive listening skills for business-related communication in English.

The work experience of these simulation participants also varied from part-time summer employment to full-time low-level managerial positions as well as mid-level regional managers in both government and private firms. Sixty percent $(60 \%)$ of participants had 5 to 15 years of work experience. Typical employers included the Hong Kong Housing Authority, American Standard, Hong Kong Bank, and various small-to medium-size Chinese firms. There were 45 male and 21 female participants.

\section{Procedures}

The computer-mediated simulation used in the study was a replication of a manufacturing industry producing and selling 
consumer durable goods (Cotter \& Fritzsche, 1991). The 11 groups competed in a business policy game that used this computer simulation. The teams assumed the roles of the top management of individual companies in an industry. Although not formally required by the simulation exercise, the groups designated roles for individual members, such as president, finance manager, marketing manager, human resources manager, and sales manager.

The simulation provided the setting for the development of realistic business dialogs. The competing teams held a series of meetings to develop and execute corporate strategies. Quarterly decisions representing the evolving firm strategies were made in the following eight areas: pricing and advertising, salespeople, finance, product models, research and development, product scheduling, plant construction and expansion, and sales (Cotter \& Fritzsche, 1991, pp. 11-26). Because of the interactive nature of the computer model underlying the simulation, a decision made by one firm influenced not only the financial and competitive position of that company, but also that of its competitors.

All of the required decision-making meetings were held and videotaped in videotaping studios equipped with professional facilities. To create a comparison of L1 and L2 communication, the groups used English (designated as a second language) and Cantonese (first language) in the designated meetings. The meetings held in English were transcribed verbatim in English and the meetings in Cantonese were transcribed in colloquial Cantonese. The transcripts for individual decision-making meetings held in English ranged between 25 and 35 pages for each group, whereas for the Cantonese meetings, the transcripts were between 30 and 50 pages for each decision-making meeting.

In total, 36 one-hour group decision-making meetings were collected and transcribed. Of 36 transcribed decision-making meetings, 19 were in Cantonese and 17 were in English. Due to missing data arising from technical problems, only the first Cantonese and English meetings were incorporated for analysis in this study. Twenty-two (22) comparable meeting transcripts (11 each in English or Cantonese meetings) were chosen for analysis. The corpus of English meetings is 65,397 words while the corpus of the Chinese meetings contains 120,998 Chinese characters. The dialogs of the 22 meetings were carefully coded for further analysis of role behaviors.

\section{Classification of the Role Behaviors}

Using the schema developed by Benne and Sheats (1948) and Barker et al. (1995), the number and frequency of the role behaviors of each participant were codified, counted, and compared. Two research fellows were employed to codify the role behaviors. To increase the degree of inter-rater reliability, each transcript was coded by the two research fellows and the norming technique was also employed to resolve the discrepancy. The results were compared to ensure a uniform standard. The analysis of 11 groups focused on role behaviors in both L1 (Cantonese) and L2 (English) meetings. The utterance of each turn was related to one of the three major role categories (i.e., task- facilitating, relational-maintenance, and self-oriented) and further classified into sub-role categories (e.g., information giving (IG), opinion seeking (OS), etc.). For example, an utterance such as "Now our inventory level is about 101 which is rather high in some sense" falls under task-facilitating role, and " $T$ " is assigned. In the same token, the sub-role behavior was assigned according to its category; that is "Information Giving". Taken together, the utterance was categorized as TIG meaning task facilitating IG. Once the dialogs were categorized by major and sub- role categories, the role behaviors were calculated and compared between the two interconnected L1 and L2 meetings.

To avoid the difficulty in matching the discourses with the two identified broad categories, each major category was divided into several sub-roles (Barker et al., 1995). The codification and classification were based on the utterances of individual participant and on the changing of sub-roles performed by individual's speech acts. For example, the President initiated topics regarding the company's strategic issues in the coming quarter. During the discussion of the turn, the President's utterance contained 8 sentences, followed by the Finance Manager's 6 sentences, and the Marketing Manager's 6 sentences respectively. In total, this communication exchange contained 20 sentences. Of these 20 sentences, the first 5 sentences matched the category of "information giving", and the next 2 sentences fit the category of "information seeking". Sentence 8 was categorized as IG and opinion giving (OG). Sentences 9 and 10 were "opinion seeking", followed by sentences 11 to 13 , which were categorized as "encouraging". Sentences 14 and 15, 16 and 17, and 18 and 20 were categorized as OG, IG, and OG, respectively. The total number of the sub-role behaviors was counted as $8 \mathrm{IG}, 2$ information seeking (IS), 2 OS, 6 OG, and 3 encourager (EN). Eighteen of the sub-roles were classified under task-facilitating role behavior and 3 were classified as relational-maintenance role behavior. The number of role behaviors was recorded as "18 task- facilitating role behaviors" and " 3 relational-maintenance role behaviors" in that President contributed 6 TIG, 4 TOG, and 3 GEN, whereas both Finance Manage and Marketing Manager contributed 2 TIS and 2 TOG (Figure 1 for example).

\section{Data Analysis}

Research Question 1 was tested by comparing the number of role behaviors that fit the task- facilitating, relational-maintenance 


\begin{tabular}{|c|c|c|c|c|}
\hline Sentence sequence & Spoken by & Individual utterances & Frequency of role behavior & Coded sub-role behavior \\
\hline $1-5$ & President & 5 sentences & 5 & Information giving \\
\hline $6-7$ & Finance manager & 2 sentences & 2 & Information seeking \\
\hline 8 & President & 1 sentence & $1+1$ & Information giving + opinion giving \\
\hline 9-10 & Marketing manager & 2 sentences & 2 & Opinion seeking \\
\hline $11-13$ & President & 3 sentences & 3 & Encouraging \\
\hline $14-15$ & Finance manager & 2 sentences & 2 & Opinion giving \\
\hline $16-17$ & Marketing manager & 2 sentences & 2 & Information giving \\
\hline $18-20$ & President & 3 sentences & 3 & Opinion giving \\
\hline
\end{tabular}

Figure 1. A sample classification of role behaviors.

role behaviors as described by Barker et al. (1995) in L1 (Cantonese) and L2 (English) meetings. Research Question 2 examines whether individuals with higher second-language proficiency exhibit more task-facilitating role behaviors, while individuals with lower second-language proficiency are likely to exhibit more relational-maintenance and/or self-oriented role behaviors.

To answer Research Question 2, Univariate Analysis of Variance (ANOVA) was employed to measure the significance of task-facilitating and relational-maintenance role behaviors performed by individuals with high L2 proficiency as compared to those with low L2 proficiency. The L2 proficiency was determined by self-reports. Based on a 7-point Likert scale, individuals rated their English proficiency level with high scores meaning high proficiency. There were two items on the self-assessment sheet that asked participants to rate their oral and their writeten proficiency. The individual's oral proficiency was employed for analysis. In addition, I also examine whether the task-facilitating role behaviors are more evenly distributed in Cantonese meetings than in English meetings. In so doing, the number of task-facilitating role behaviors performed by individuals is plotted and compared with their distribution between Chinese and English meetings.

For Research Question 3, Pearson Correlation Coefficients was employed to measure whether individuals who exhibited high task-facilitating role behaviors in English meetings also exhibited high task-facilitating role behaviors in Cantonese meetings.

\section{Results}

\section{Findings for Research Question 1}

Research question 1 asked whether Hong Kong bilingual Chi- nese exhibited different role behaviors in interconnected firstand second-language decision-making meetings. To answer this question, a paired sample t-test was performed to compare whether there was any significant difference between the English and Cantonese meetings with regard to their performed role behaviors. The mean scores of the task-facilitating role behaviors in English and Cantonese meetings were 49.98 and 60.82 respectively, whereas the mean scores of relational-maintenance role behaviors in English and Cantonese were 7.91 and 8.60 respectively. The findings revealed that the respective task- facilitating role behaviors between English and Cantonese meetings is significant $(t=1.75, p<.01)$ whereas the relational-maintenance role behaviors were not significant $(t=$ $0.5, p>.01)$. Although no significant difference was found in the relational-maintenance role behaviors between L1 and L2 meetings, Hong Kong bilingual Chinese exhibited slightly more relational-maintenance role behaviors when conducting their decision-making in their first language, i.e. Cantonese, (mean score $=8.60)$ as compared to when conducting meetings in their second language, i.e. English (mean score $=7.91$ ).

The result also showed that task-facilitating role behaviors were more prominent than relational- maintenance role behaviors no matter whether the participants were making decisions in their first language (mean scores $=60.82$ and $8.56, p<.001$ ) or in their second language (mean scores $=49.98$ and 7.91, $p<.001$ ). In this connection, completing a task, rather than maintaining group relations, was the primary purpose of a meeting. Of 12 sub-roles of the task-facilitating role behaviors, there were four dominant role behaviors which consist of $33.3 \%$ of the total role behaviors. Participants played more information-giving roles (mean difference $=11.04, p<.001)$ and elaborating roles (mean 
difference $=3.09, p<.01)$ in L1 than L2 meetings. However, participants displayed the role of gatekeeper more prominently in $\mathrm{L} 2$ meetings than in L1 meetings (mean difference $=0.44, p<.05$ ).

A significant difference was found between the role of an IG and an OG (mean difference $=9.46, p<.001$ ) in L1 meetings. Nevertheless, there was no significant difference between these two role behaviors in L2 meetings. But in L2 meetings, the role behavior of IG (mean score $=16.50$ ) is still more obvious than that of OG (mean score $=15.58$ ).

In sum, task-facilitating role behaviors were more prominent than relational-maintenance role behaviors no matter whether the participants made decisions in L1 (mean difference $=58.11$, $p<.001$ ) or L2 (mean difference $=40.29, p<.001$ ). The results indicated that completing the designated task was the primary concern at the meeting.

\section{Findings for Research Question 2}

Research question 2 asked whether bilinguals with higher second-language proficiency exhibited more task-facilitating role behaviors, while bilinguals with lower second-language proficiency tended to exhibit more relational-maintenance role behaviors. The results showed that individuals possessing high second-language proficiency had a tendency to perform more task-facilitating role behaviors in the English meetings as compared to those with lower second-language proficiency ( $F$ $=4.01, p<.05)$. However, the result indicates that there was no significant difference in relational- maintenance role behaviors between individuals with high and low second-language proficiency $(F=0.00, p>.05)$. It means that the second language proficiency does nothing with their relational- maintenance role behaviors either in L1 or L2 meetings.

To further examine whether the role behaviors were more evenly distributed by Hong Kong bilingual Chinese in their L1 meeting, the frequency of the role behaviors performed by all the participants are plotted and the comparisons are made between English and Cantonese meetings (Figure 2). In comparison, with the distribution between Cantonese and English meetings, the bell curve distribution shows that the task-facilitating role behaviors were more evenly distributed in English decision-making meetings than those in Cantonese meetings $(S D=42.7$ and 64.9 , respectively). The reason for such a conflicting result might be due to the fact that the nature of the decision-making meeting is mainly task-oriented. In order to optimize the decision-making, all the members must participate and perform task-facilitating role behaviors in the meetings. One plausible explanation for the slightly more evenly distributed behavior in English meetings can be the out-of-meeting first- language communication. This unexpected finding of out-



Figure 2. The distribution of the task-facilitating role behaviors in cantonese and English meetings.

of-meeting communication maximized the success of the second-language meetings. It might be that at the second-language decision-making meetings, all the participants simply reported their prepared data. To most of the participants, meetings were set up for motion and acting out their earlier discussions.

In contrast, when using first language to report and discuss, the participants did not refrain from expressing their viewpoints. Thus, the distribution of the role behaviors exhibited in Cantonese meetings was wider than that in English meetings. In other words, individuals who were well prepared for the meetings were likely to perform more actively in task-facilitating role behaviors as the participants were not inhibited by the language used in expressing their opinions.

\section{Findings for Research Question 3}

Research Question 3 asks whether language proficiency affects the role behavior of Hong Kong bilingual Chinese. To answer this research question, Pearson Correlation Coefficient was employed to investigate the possible positive correlation between L2 proficiency and the performance of task- facilitating role behaviors. A significant positive correlation was found between L2 proficiency and task-facilitating role behaviors in L2 meetings $(r=0.34, p<.001)$. However, there is no significant correlation between L2 proficiency and relational-maintenance role behaviors. The finding also reveals that individuals who performed more actively in task-facilitating role behaviors in English meetings (mean difference $=76.83, p<.05$ ) would also perform 
more actively in task-facilitating role behaviors in Cantonese meetings (mean difference $=61.57, p<.05$ ). Similar patterns are applied to the participants' performance of the relational-maintenance roles.

\section{Discussion}

\section{Implications}

Against the background of the findings and limitations of the current study, I recommend that future research investigate and more precisely define how bilingual Chinese (as well as individuals from other high-context cultural societies) with varying second-language competencies communicate in a language environment where English or another low-context language is a dominant language.

These studies could better define how to structure a communication environment to solicit the involvement of second-language speakers with intermediate second-language proficiency in intercultural small-group meetings. As such, these future studies could be structured to investigate how bilinguals from high-context cultural societies (e.g., Japan, Taiwan, Hong Kong) communicate in a language environment where English is the dominant mode of communication and where the bilinguals do not have ready access to other native speakers speaking the same native language.

This current study clarifies when and why bilinguals (in this Hong Kong bilingual case) communicate differently in their first- and second-language meetings in a language environment where they have ready and easy access to other Cantonese first-language speakers. The current study provides possible markers for improving both the quantity and quality of intercultural communication in which bilinguals with varying second-language proficiency participate in international business communication. When bilinguals with intermediate second-language proficiency participate in an intercultural small-group meeting requiring interactive decision making, the challenge is to create a communication structure where their communication potential is more fully utilized.

\section{Limitations}

The research design of the present study did not anticipate that out-of-meeting discussions would become a major part of the communication system of the Cantonese bilinguals when making decisions in their second language (English). The research design was set up to measure comparable meetings in first and second languages. The first-language meetings were relatively complete as the bilingual participants conducted meetings from scratch and used the allocated meeting time to interact among themselves and finalize the quarterly decisions. In the second-language meetings, it is possible that the bilinguals simply went through the motions and confirmed the decisions that had been made in their native language outside of the video-taping meetings. Because the research design only measured in-meeting communication, it did not capture all of the relevant bilingual communication. It was only through the focus- group discussion that the participants disclosed the importance that they attached to their first-language communication whether it took place in or out of the scheduled meetings.

Another limitation can be the use of a business game to generate dialogs. Some may argue that in simulations, the participants communicate and make decisions that are not influenced by the realities of the real-world business environment, and therefore, data on their communication and decision-making patterns can only yield unrealistic and misleading conclusions. Although simulated data has been widely used in the field of business and professional communication, the controversy of whether the simulated data can reflect genuine practices of the real-world business has been debated for decades. Researchers confronting the authenticity of the simulated data criticize that simulated data is produced in a decontextualized environment (Firth, 1995; Kasper, 2000). Other researchers regard simulated data are comparable to authentic data support that simulation enables research to be conducted in an "artificially created but not too different from reality" environment (Sekaran \& Bougie, 2014, p. 188). Although the goal of a simulated interaction is predetermined, the participants have to accomplish the actions through talk, and therefore the interaction per se is spontaneous and locally managed by the participants (Kasper, 2000), and can demonstrate various communicative features which are also observed in natural interaction (Félix-Brasdefer, 2010). As Planken (2012) noted, well designed simulated data can "serve as the best alternative" to authentic data. Moreover, simulation enables researchers to repeat the same activity with different combinations of participants so that researchers can develop a more general picture of the research activity and test the cause and effect relationship between dependent and independent variables (Félix-Brasdefer, 2010; Sekaran \& Bougie, 2014, van der Wijst \& Ulijn, 1995).

A study by Du-Babcock and Chan (2019) explored the extent to which interaction in simulated data can manifest authentic practices in the business world. Their findings suggest that there is a considerable degree of similarities between the simulated and authentic types of meetings in terms of the use of communicative strategies while the differences are also observed in the authentic discourse used to accomplish the chairing activities. Their findings also confirm that the use of business profession- 
als may be able to compensate for the use of simulated data. In sum, Du-Babcock and Chan's (2019) study suggest that simulated data can be comparable to authentic data when the activity being studied is commonly practiced and when participants with relevant experience are recruited.

Although a great number of the past research has shown that the data collected via simulations and business games has yielded valid data (Abdel-Khalik, 1974; Alpert, 1967; Ashton \& Kramer, 1980; Eijkman, 2012; Johnson, Smith, Willis, Levine, \& Haywood, 2011), the use of authentic dialogs from bilingual managers in business firms is preferable. This limitation was mitigated in the present study by the quasi- experimental design that made possible the direct comparison of bilinguals' firstand second- language communication and role behaviors.

\section{Conclusion}

The study measured and contrasted the task-facilitating and relational-maintenance role behaviors in Cantonese (L1) and English (L2) strategic decision-making meetings. The results showed that Hong Kong bilingual Chinese performed more task-facilitating and relational-maintenance role behaviors in Cantonese meetings than in English meetings. The findings also revealed that second-language proficiency influenced the task-facilitating role behaviors when making decisions in English and that the individuals who performed more task-facilitating role behaviors in English meetings had a tendency to perform more task-facilitating role behaviors in Cantonese meetings.

In order to put the study's findings in the proper perspective, I wish to put forth a caution in regard to the results interpreted as the relational-maintenance role behaviors which may be understated in the second-language meetings. In effect, some relational-maintenance role behaviors were accomplished ahead of time in private Cantonese meetings in which the second- language meetings were planned and may have been rehearsed outside of the recoding meetings. This phenomenon can sometimes be observed in intercultural meetings where the second-language speakers are likely to rehearse their viewpoints before the actual meeting occurs.

\section{References}

Abdel-Khalik, A. (1974). On the efficiency of subject surrogation in accounting research. Accounting Review, 49(4), 743-750.

Alpert, B. (1967). Non-businessmen as surrogates for business in behavioral experiments. The Journal of Business, 40(2), 203-207.

Ashton, R. H., \& Kramer, S. S. (1980). Students as surrogates in behavioral accounting research: Some evidence. Journal of Ac- counting Research, 18(1), 1-15.

Bales, R. (1950). Interaction process analysis: A method for the study of small groups. Cambridge, MA: Addison-Wesley.

Bales, R. (1958). Task roles and social roles in problem-solving groups. In E. Maccoby, T. Newcomb, \& E. Hartly (Eds.), Readings in social psychology (pp. 437-447). New York, NY: Hit, Renehart $\&$ Winston.

Barker, L., Wahlers, K., Watson, K., \& Kibler, R. (1995). Groups in process: An introduction to small group communication (5th ed.). Englewood Cliffs, NJ: Prentice-Hall.

Bavelas, A. (1950). Communication patterns in task oriented groups. The Journal of the Acoustical Society of America, 22(6), 725-730.

Benne, K. D., \& Sheats, P. (1948). Functional roles of group members. Journal of Social Issues, 4(2), 41-49.

Bilbow, G. (1996). Managing impressions in the multicultural workplace: An impression- management-based model for cross-cultural discourse analysis and awareness training for the workplace (Doctoral dissertation). City University of Hong Kong, Hong Kong.

Bilbow, G. T. (2002). Commissive speech act use in intercultural business meetings. International Review of Applied Linguistics in Language Teaching, 40(4), 287-303.

Chen, A. S. Y., Lin, Y., \& Sawangpattanakul, A. (2011). The relationship between cultural intelligence and performance with the mediating effect of culture shock: A case from Philippine laborers in Taiwan. International Journal of Intercultural Relations, 35(2), 246-258.

Cotter, R. V., \& Fritzsche, D. J. (1991). The business policy game: Player's manual (3rd ed.). Englewood Cliffs, NJ: Prentice-Hall.

Diedrich, R. C., \& Dye, H. A. (Eds.). (1972). Group procedures: Purposes, processes and outcomes. Boston, MA: Houghton Mifflin.

Du-Babcock, B. (1999). Topic management and turn-taking in professional communication: First versus second-language strategies. Management Communication Quarterly, 12(4), 544-574.

Du-Babcock, B. (2003). A comparative analysis of individual communication processes in small group behavior between homogeneous and heterogeneous groups. Proceedings of the 68th Association of Business Communication Convention (pp. 1-16). Albuquerque, NM.

Du-Babcock, B. (2005). An analysis of communication behaviors between intra-and inter-cultural decision-making meetings. In F. Bargiela-Chiappini, \& M.O. Gotti (Eds.), Asian business discourse(s) (pp. 147-168). New York, NY: Peter Lang.

Du-Babcock, B. (2006). An analysis of topic management strategies and turn-taking behavior in the Hong Kong bilingual environment: The impact of culture and language use. The Journal of Business Communication, 43(1), 21-42.

Du-Babcock, B. (2013). English as business lingua franca: A com- 
parative analysis of communication behavior and strategies in Asian and European contexts. Ibérica, 26, 99-130.

Du-Babcock, B., \& Babcock, R. (1996). Patterns of expatriate-local personnel communication in multinational corporations. The Journal of Business Communication, 33(2), 141-164.

Du-Babcock, B., \& Chan, A. C. K. (2019). A commentary on the use of simulated settings in business communication research. International Journal of Business Communication. doi: $10.1177 / 2329488419878863$.

Du-Babcock, B., \& Tanaka, H. (2013). A comparison of the communication behaviors of Hong Kong Chinese and Japanese business professionals in intracultural and intercultural decision-making meetings. Journal of Business and Technical Communication, 27(3), 263-287.

Félix-Brasdefer, J. C. (2010). Data collection methods in speech act performance. In A. Martinez-Flor, \& E. Usó-Juan (Eds.), Speech act performance: Theoretical, empirical and methodological issues (pp. 41-56). Amsterdam, The Netherlands: John Benjamins.

Firth, A. (1995). Introduction and overview. In A. Firth (Ed.), The discourse of negotiation: Studies of language in the workplace (pp. 3-39). Oxford, UK: Pergamon.

Hare, A. P., \& Davies, M. F. (1994). Social interaction. In A. P. Hare, H. H. Blumber, M. F. Davies, \& M. V. Kent (Eds.), Small group research: A handbook (pp. 169-193). Norwood, NJ: Ablex.

Hirokawa, R. (1988). Group communication and decision-making performance: A continued test of the functional perspective. $\mathrm{Hu}$ man Communication Research, 14(4), 487-515.

Johnson, L., Smith, R., Willis, H., Levine, A., \& Haywood, K. (2011). The 2011 horizon report. Austin, TX: New Media Consortium. Retrieved from https://library.educause.edu/resources/2011/2/2011-horizon-report

Kasper, G. (2000). Data collection in pragmatics research. In H. Spencer-Oatey (Ed.), Culturally speaking: Managing rapport through talk across cultures (pp. 316-341). London, UK: Continuum.

Nickerson, C. (2005). English as a lingua franca in international business contexts. English for Specific Purposes, 24(4), 367-380.
Perks, H., Cooper, R., \& Jones, C. (2005). Characterizing the role of design in new product development: An empirically derived taxonomy. Journal of Product Innovation Management, 22(2), 111-127.

Planken, B. (2012). The changing landscape of business communication: Developments and directions in research. In P. Heynderickx, S. Dieltjens, G. Jacobs, P. Gillaerts, \& E. de Groot (Eds.), The language factor in international business: New perspectives on research, teaching and practice (pp. 17-40). Bern, Switzerland: Peter Lang.

Pugh, D. S, \& Redding, S. G. (1985, January). A comparative study of the structure and context of Chinese business in Hong Kong. Paper presented at the Association of Teachers of Management Research Conference. Ashridge, UK.

Rogerson-Revell, P. (1999). Meeting talk: A stylistic approach to teaching meeting skills. In M. Hewings \& C. Nickerson (Eds.), Business English: Research into practice (pp. 55-72). London, UK: Longman.

Rogerson-Revell, P. (2008). Participation and performance in international business meetings. English for Specific Purposes, 27(3), 338-360.

Rose, R. C., Ramalu, S. S., Uli, J., \& Kumar, N. (2010). Expatriate performance in international assignments: The role of cultural intelligence as dynamic intercultural competency. International Journal of Business and Management, 5(8), 76-85.

Sekaran, U., \& Bougie, R. (2014). Research methods for business: A skill-building approach (6th ed.). Hoboken, NJ: John Wiley \& Sons.

van der Wijst, P., \& Ulijn, J. (1995). Politeness in French/Dutch Negotiations: The linguistic realisation of politeness strategies. In $\mathrm{K}$. Ehlich, \& J. Wagner (Eds.), The discourse of international negotiations (pp. 313-348). New York, NY: Walter de Gruyter.

Westwood, R. I. (1992). Organizational behavior. Southeast Asian perspectives. Hong Kong: Longman.

Yamada, H. (1990). Topic management and turn distribution in business meetings: American versus Japanese strategies. Text, 10(3), 271-295. 


\section{Appendix}

Appendix 1. Twelve sub-roles of task-facilitating role behaviors

\begin{tabular}{|c|c|}
\hline Sub-role behavior & Role function and example \\
\hline Information giver & $\begin{array}{l}\text { Provides factual information to the group and answer to questions or queries. The information giver is seen as an au- } \\
\text { thority on the subject area and tends to relate own experience when relevant. (e.g., Now our inventory level is about } \\
101 \text { which is rather high in some sense.) }\end{array}$ \\
\hline information seeker & $\begin{array}{l}\text { Requests information in that the seeker requests clarification of comments in terms of their factual adequacy. The infor- } \\
\text { mation seeker not only seeks expert information, and also determines what information is missing and that needs to } \\
\text { be found before moving forward. (e.g., Should we cut the price? So you will cut the price to ...?) }\end{array}$ \\
\hline Orienteer & $\begin{array}{l}\text { Orients the group by introducing the agenda and define goals and procedures in that the orienteer reviews and clarifies } \\
\text { the group's position. The role of the orienteer is to keep the group focused and the discussion on track. In doing so, the } \\
\text { orienteer summarizes the essence of the group discussion, notes where the group discussion is off the track, and sug- } \\
\text { gests how to get back on target. (e.g., May I remind you that our mission is the top sales?) }\end{array}$ \\
\hline Initiator/contributor & $\begin{array}{l}\text { Seeks new ideas and makes proposal about how to pose original ideas or different ways of approaching problems or } \\
\text { goals on different perspectives. This role initiates discussions and move groups into new areas of exploration. (e.g., Let's } \\
\text { talk about the production department.) }\end{array}$ \\
\hline Opinion giver & $\begin{array}{l}\text { Expresses individual opinions and beliefs that are related to the task. The opinion giver often states opinions in terms of } \\
\text { what the group "should" do. (e.g., so I think if we want to achieve the cost leadership in the market, we have to cut our } \\
\text { price at least not higher than other company.) }\end{array}$ \\
\hline Opinion seeker & $\begin{array}{l}\text { Asks for clarification of the group members' opinions of. The role of the opinion seeker checks to ensure different per- } \\
\text { spectives are spoken. (e.g., What do you think we should achieve..er... Jay? Do you think that the inventory should be } \\
\text { kept at the lowest possible level?) }\end{array}$ \\
\hline Elaborator & $\begin{array}{l}\text { Builds on one another's ideas and suggestions with examples, relevant facts and data. The role of the elaborator tends } \\
\text { to also examine the consequences of proposed ideas and actions. (e.g., It means that you will keep the quality at the } \\
\text { standard level.) }\end{array}$ \\
\hline Coordinator & $\begin{array}{l}\text { Not only identifies the relationships between ideas, but also pulls together a few different ideas and makes them cohe- } \\
\text { sive. (e.g., And as Mandy has said the cost of the new plant is } 2.6 \text { million and we can divide that into } 5 \text { installment.) }\end{array}$ \\
\hline Evaluator-critic & $\begin{array}{l}\text { Evaluates the ideas against a predetermined objectives or standards. The role of evaluator-critic also examines the fea- } \\
\text { sibility of a proposal as to determine whether it is fact-based and manageable as a solution. (e.g., But don't forget that } \\
\text { we have } 2 \text { additional new lines adding to the production.) }\end{array}$ \\
\hline Energizer & $\begin{array}{l}\text { Stimulates group involvement. The energizer challenges and stimulates the group to further action. (e.g., Let's come up } \\
\text { with the conclusion.) }\end{array}$ \\
\hline Procedural technician & $\begin{array}{l}\text { Takes on routine tasks. The procedural technician facilitates group discussion by taking care of logistical concerns, such } \\
\text { as when and where the next meetings are to take place, and the deadlines of actions to be accomplished by each indi- } \\
\text { vidual member. (e.g., That's the end of our meeting.) }\end{array}$ \\
\hline Recorder & Acts as the Secretary or Minute-Keeper. Records ideas and keeps track of what goes on at each meeting. \\
\hline
\end{tabular}

Appendix 2. Seven sub-roles of group building and maintenance role behaviors

\begin{tabular}{|c|c|}
\hline Sub-role behavior & Role function and example \\
\hline Harmonizer & $\begin{array}{l}\text { Relives tension, mediates disputes, and reconciles disagreements. (e.g., What do you mean by that, financial } \\
\text { manager? (all laugh)) }\end{array}$ \\
\hline Compromiser & $\begin{array}{l}\text { Finds common ground, gives individual opinions and accommodates to other members' desires. Consequently, the } \\
\text { compromiser seeks a middle-ground solution. (e.g., But anyway we will do something.) }\end{array}$ \\
\hline Gatekeeper & $\begin{array}{l}\text { Expedites and keeps communication channels open to ensure all people have a chance to express ideas and feelings. } \\
\text { (e.g., Jay, what is your opinion? So shall we ask our personnel department to, to, eh, consider the....) }\end{array}$ \\
\hline Follower & $\begin{array}{l}\text { Accepts others' ideas and serves as audience. (e.g., OK. We accept your explanation. OK. I concurred with your } \\
\text { viewpoints.) }\end{array}$ \\
\hline Encourager & $\begin{array}{l}\text { Helps quiet group member to make his or her point by establishing a supportive and encouraging climate. (e.g., Yes, I } \\
\text { also think so. Yeah. Intention, I think, is good.) }\end{array}$ \\
\hline Confirmer & $\begin{array}{l}\text { Confirms / repeats the points made by other members to ensure his understanding is correct. (e.g., } 40,40 \text {, and } 46 \text {, } \\
\text { yes, right?) }\end{array}$ \\
\hline Response giver & $\begin{array}{l}\text { Taking the role of being responsive (BR) respond actively to member's opinion to show appreciation or } \\
\text { understanding. (e.g., Yes, OK, I see...; Ok, thank you; thank you Mr. So and So. The pricing policy has been agreed, eh, } \\
\text { the employment has been agreed.) }\end{array}$ \\
\hline
\end{tabular}

